\title{
Multiple gas detection by dynamic electrochemical methods
}

\author{
A. Ruchets ${ }^{1}$, N. Donker ${ }^{2}$, D. Schönauer-Kamin'2, R. Moos ${ }^{2}$, J. Zosel' ${ }^{1}$ U. Guth ${ }^{3}$, M. Mertigi,3 \\ ${ }^{1}$ Kurt-Schwabe-Institut für Mess- und Sensortechnik Meinsberg e.V., Kurt-Schwabe-Straße 4, \\ 04736 Waldheim, Germany \\ ${ }^{2}$ Department of Functional Materials, University of Bayreuth, Universitätsstraße 30, 95440 Bayreuth, \\ Germany \\ 3Institute of Physical Chemistry, Technische Universität Dresden, 01062 Dresden, Germany \\ anastasiya.ruchets@ksi-meinsberg.de
}

\begin{abstract}
Summary:
Multiple redox gas detection such as carbon monoxide, nitrogen monoxide and oxygen by solid electrolyte gas sensors (SESs), operated in a dynamic detection regime, is reported. To this aim, an oxygenpumping SES was used in cyclic voltammetry mode at different operational conditions and gas concentrations. The obtained results demonstrate the possibility of selective detection of $\mathrm{CO}$ and $\mathrm{NO}$ in nitrogen gas flow with one device.
\end{abstract}

Keywords: Yttria-stabilized zirconia (YSZ), carbon monoxide, nitrogen oxide, cyclic voltammetry, solid electrolyte sensor (SES)

\section{Motivation}

One common source of toxic gas exposure is the incomplete combustion of fuels in combustion engines. Exhaust gases usually contain mixtures of redox-active gases, for example $\mathrm{CO}$ and NO. In order to detect such redox active gases selectively and simultaneously, electrochemical sensors operated in dynamic mode can be applied. The advantage of dynamic measurements is the utilization of different electrode reaction kinetics, which are not visible in static mode of operation with signals corresponding to the total equilibrium between the gases $[1,2]$.

In the presented work, a Pt/YSZ/Pt-based solid electrolyte gas sensor is used for multiple redoxactive gas detection by means of dynamic electrochemical measurements for the example of cyclic voltammetry in combination with static open circuit potential measurements in the gas outflow.

\section{Experimental setup}

The set-up described in [3] was modified to establish and detect $\mathrm{NO}, \mathrm{CO}$, and $\mathrm{O}_{2}$ concentrations in nitrogen gas flow (see Figure 1). The total flow rate and the analyte concentrations were regulated by mass flow controllers. In contrast to this control, the $\mathrm{O}_{2}$ concentrations were established by means of constant polarization of SES 1. All dynamic electrochemical measure-

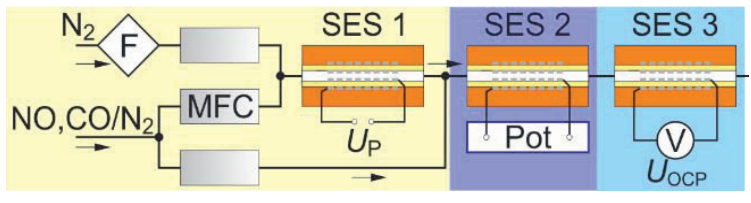

Fig. 1. Experimental setup. MFC - mass flow controller, SES - solid electrolyte sensor, Pot - electrochemical measuring system, $F$ - triple filter.

ments were carried out in SES 2 at different experimental settings. SES 3 was used to measure open circuit potentials in the outlet gas.

\section{Results}

The curves given in Figure 2 show cyclic voltammograms (CVs) recorded at SES 2 at $700^{\circ} \mathrm{C}$ in dry gas flow with a mixture of different concentrations of $\mathrm{CO}$ and $\mathrm{NO}$ and at $c\left(\mathrm{O}_{2}\right)=65 \mathrm{ppmv}$ in $\mathrm{N}_{2}$. The gas concentrations have been changed from 150 to 0 ppmv of each gas in the mixture. For each concentration, CVs with three cycles were recorded. For NO detection every second cycle was taken, while the $\mathrm{CO}$ peak of the first cycle was taken for peak quantification.

Curves in Figure 2A were measured at a scan rate $1000 \mathrm{mV} / \mathrm{s}$, while this parameter was optimized for NO gas detection in previous work [4]. As the NO gas concentration increases, the NOrelated peak also increases (see inset in Fig. $2 \mathrm{~A}$ ), showing cross-selectivity to $\mathrm{CO}$ gas in the concentration range between 0 and 150 ppmv. 

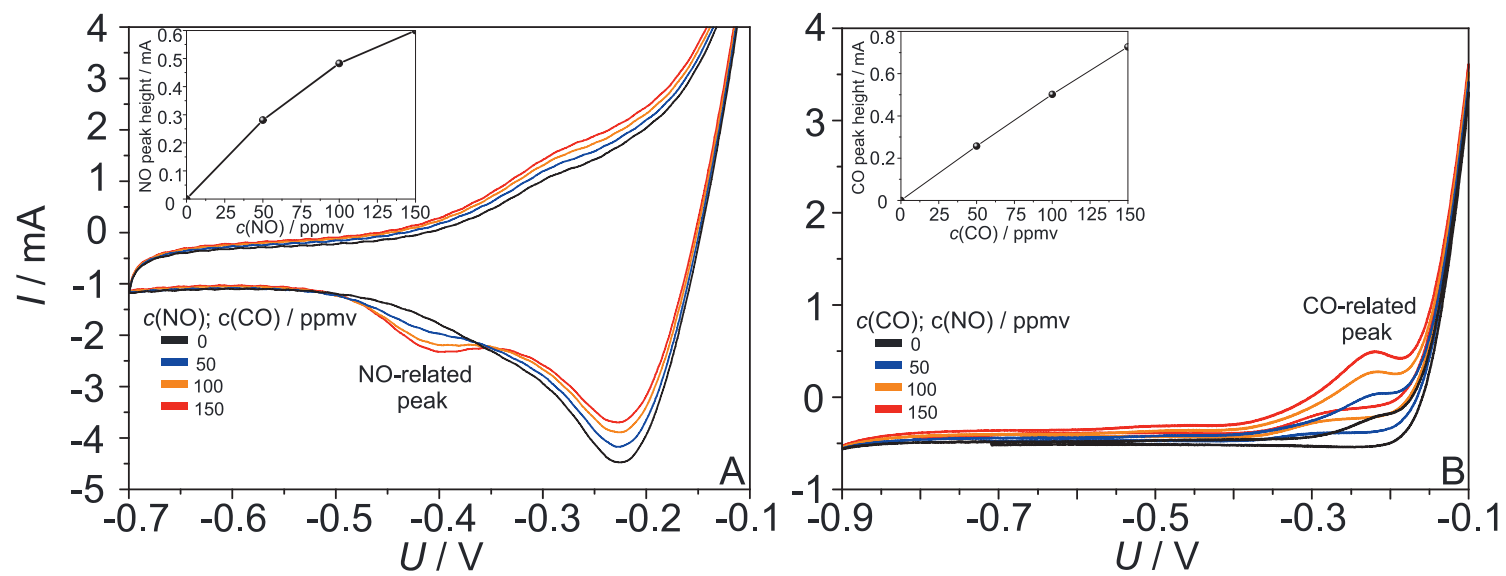

Fig. 2. Cyclic voltammograms in the gas mixture of $N O$ and CO gases diluted in nitrogen at (A) $1000 \mathrm{mV} / \mathrm{s}$ scan rate and $(B)$ at $20 \mathrm{mV} / \mathrm{s} \mathrm{scan}$ rate. Sensor temperature $T=700{ }^{\circ} \mathrm{C}$; flow rate $=20 \mathrm{sccm} ; \mathrm{c}\left(\mathrm{O}_{2}\right)=65 \mathrm{ppmv}$.

Curves in Figure 2B have been recorded at $20 \mathrm{mV} / \mathrm{s}$ scan rate, in order to detect carbon monoxide in presence of oxygen and nitrogen monoxide. Linear concentration dependency was observed for the detected CO-related peak in the concentration range between 0 and 150 ppmv.

Monitoring of the open circuit potential $U_{\text {ocp }}$ in the outlet gas during measurements and pauses between experiments is plotted in Figure 3 as a temporal course. The baseline shift due to gas concentration changes can be clearly seen on the curves as well as the changes of Uocp during each cycle of cyclic voltammograms. During taking the voltammograms at $1000 \mathrm{mV} / \mathrm{s}$ scan rate, the potential was changed to more positive values, illustrating an increase of oxygen concentration during NO detection. In contrast to that, very negative potentials, e.g. reducing conditions have been reached for $\mathrm{CO}$ detection at cyclic voltammograms at $20 \mathrm{mV} / \mathrm{s}$.

\section{References}

[1] X. Zhang, H. Kohler, M. Schwotzer, Y. Wu, U. Guth, Mixed-potential gas sensor with layered Au,Pt-YSZ electrode: Investigating the sensing

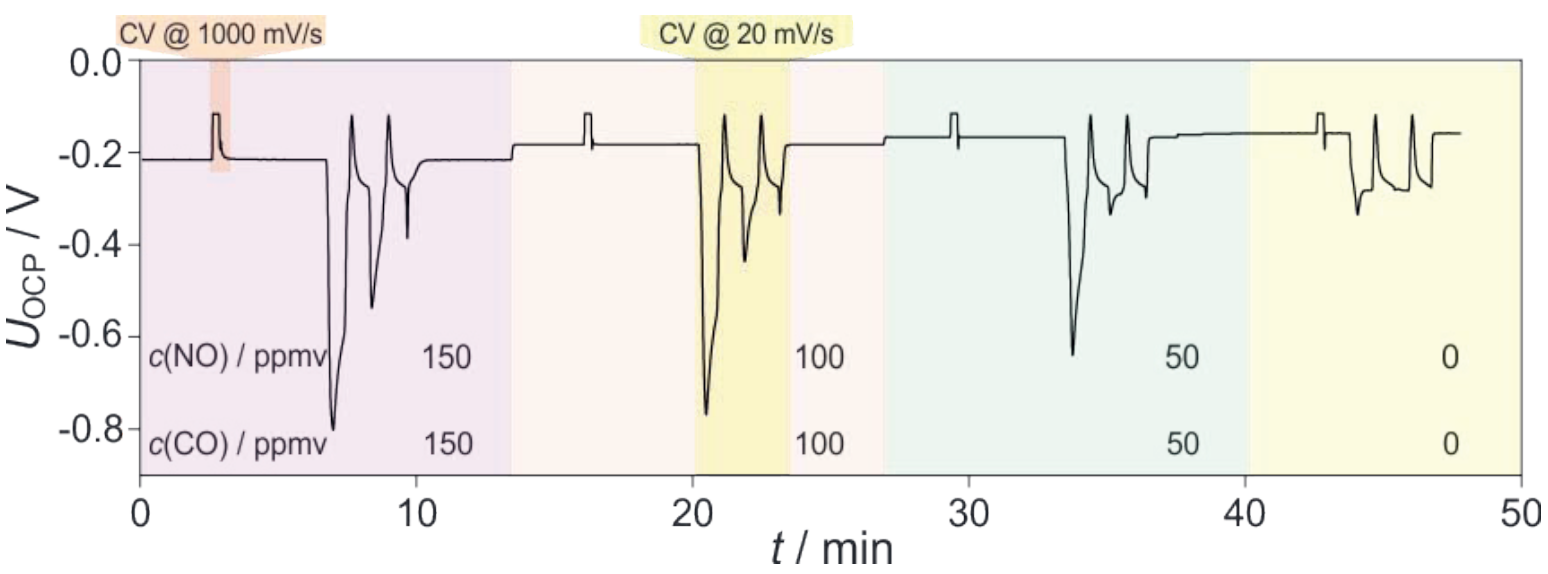

Fig. 3. OCP measurement in the outlet gas flow with SES 3. mechanism with steady state and dynamic electrochemical methods, Sensors and Actuators B: Chemical 252, 554-560 (2017); doi: 10.1016/j.snb.2017.05.168

[2] T. Ritter, J. Lattus, G. Hagen, and R. Moos, Effect of the Heterogeneous Catalytic Activity of Electrodes for Mixed Potential Sensors, Journal of The Electrochemical Society 165, B795-B803 (2018); doi: 10.1149/2.0181816jes

[3] A. Ruchets, N. Donker, D. Schönauer-Kamin, R. Moos, J. Zosel, U. Guth, M. Mertig, Selectivity improvement towards hydrogen and oxygen of solid electrolyte sensors by dynamic electrochemical methods, Sensors and Actuators B: Chemical 290, 53-58 (2019); doi: 10.1016/j.snb.2019.03.063

[4] A. Ruchets, N. Donker, D. Schönauer-Kamin, R. Moos, J. Zosel, U. Guth, M. Mertig, Cyclic and square-wave voltammetry for selective simultaneous $\mathrm{NO}$ and $\mathrm{O}_{2}$ gas detection by means of solid electrolyte sensors, Journal of Sensors and Sensor Systems 9, 355-362 (2020); doi: $10.5194 /$ jsss-9-355-2020 